\title{
Putative Deep weathering profiles in the Arctic
}

\author{
IGNACIO GONZALEZ-ALVAREZ ${ }^{1 *}$, MARCO BRøNNER ${ }^{2}$ \\ (1) CSIRO, 26 Dick Perry Avenue, Kensington WA 6151, Perth, Western Australia \\ (2) NGU, Norwegian Geological Survey, Trondheim, Norway
}

\section{INTRODUCTION}

Weathered rock profiles are widespread throughout Europe, where they form blankets often $>50 \mathrm{~m}$ thick, such as in the Scandinavian Mountains, Fennoscandian Shield, British Isles, and the central European mountain and upland belts. All of these are characterized by abundance of Mesozoic and Cenozoic geology weathered to kaolinite-rich saprolite. Remnants of deeply weathered basement rocks in Norway occur along structurally defined zones of crustal weakness, where locally-continuous saprolite layers can be up to $100 \mathrm{~m}$ in thickness. This likely had a substantial impact on the geomorphological evolution of the topography of Norway, since erosion of the sedimentary succession does not seem sufficient to explain the observed immature Alpine-type topography.
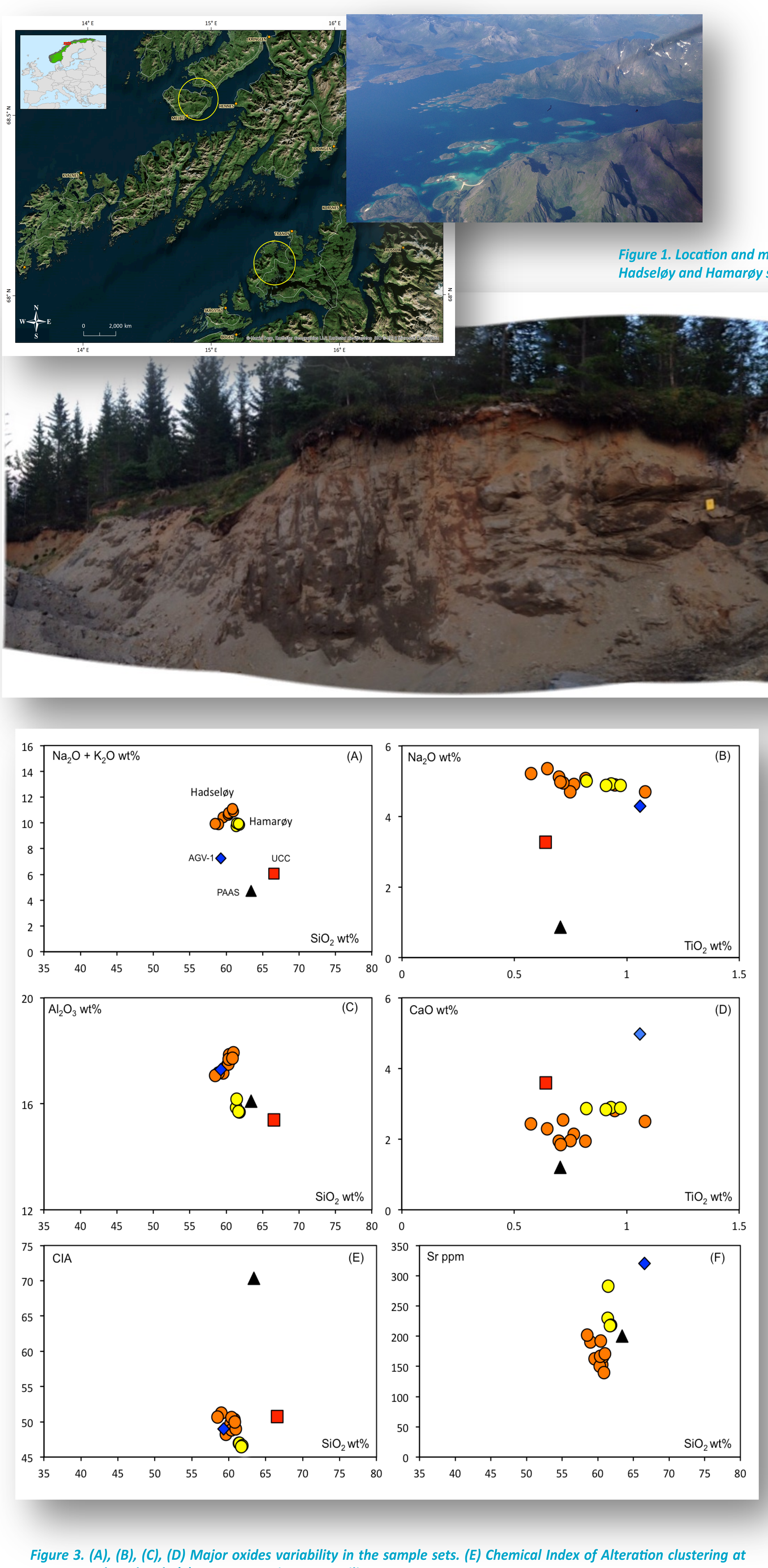

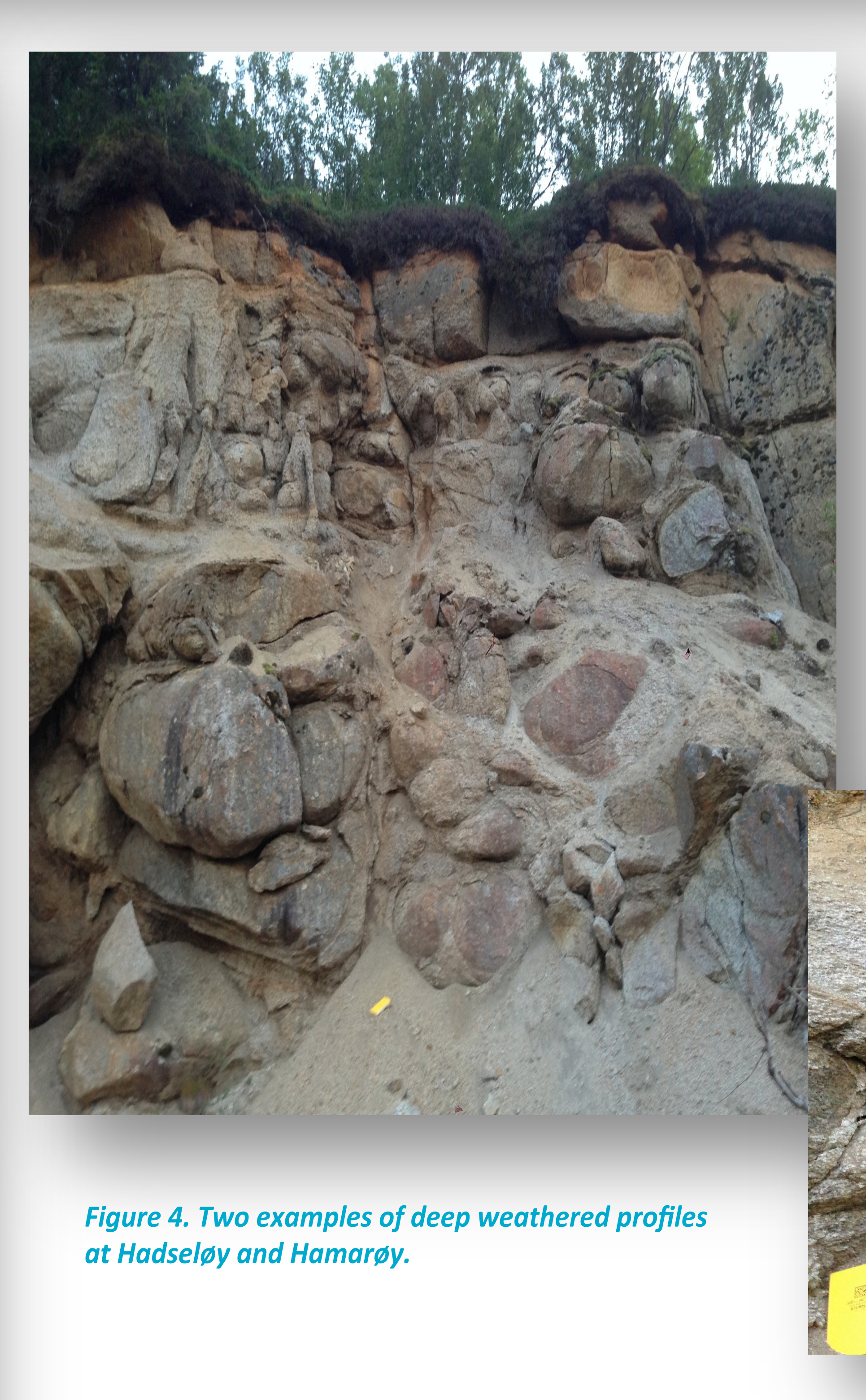

\section{RESULTS}

On the islands of Hadseløy and Hamarøy (Figs. 1 and 2), two localities within the Arctic Circle of Norway, two sites were studied that display apparently deep weathering profiles up to $\sim 30 \mathrm{~m}$ thickness, containing relic boulders preserved at different stages of spheroidal weathering. Fresh samples yield andesitic and dacitic geochemical compositions. Mineral compositions comprise of plagioclase and potassium feldspar, varying from $\sim 40-55 \mathrm{wt} \%$ and $\sim 25-30 \mathrm{wt} \%$, respectively, along with quartz $4-11 \mathrm{wt} \%$, and minor $<3 \%$ vermiculite.

In both localities, samples contain $\mathrm{Al}_{2} \mathrm{O}_{3}$ at $\sim 16 \mathrm{wt} \%, \mathrm{Na}_{2} \mathrm{O}$ at $\sim 5.0 \mathrm{wt} \%$, and $\mathrm{CaO}$ at $\sim 2.0-2.8 \mathrm{wt} \%$. $\mathrm{SiO}_{2} / \mathrm{Al}_{2} \mathrm{O}_{3}$ ratios vary from $\sim 3.4$ to 3.9 , and $\mathrm{TiO}_{2} / \mathrm{Na}_{2} \mathrm{O}$ ratios display values from $\sim 0.12-0.23$ (for Hadseløy) and $\sim 1.6-2.0$ (for Hamarøy). Chemical Index of Alteration (CIA) clusters at $\sim 50$ in both localities. La/Ce, $\mathrm{Y} / \mathrm{Ba}$ ratios display no significant variability at $\sim 0.5-0.6$ and $\sim 0.01-0.04$, respectively; and $\mathrm{Zr} / \mathrm{Sr}$ ranges from $\sim 0.6-2.5$ and $\sim 0.035$ in Hadseløy and Hamarøy, respectively. Elemental ratios of mobile to immobile elements do not fluctuate throughout the profiles (Figs. 3 , 4 and 5).

Deep weathered profiles?

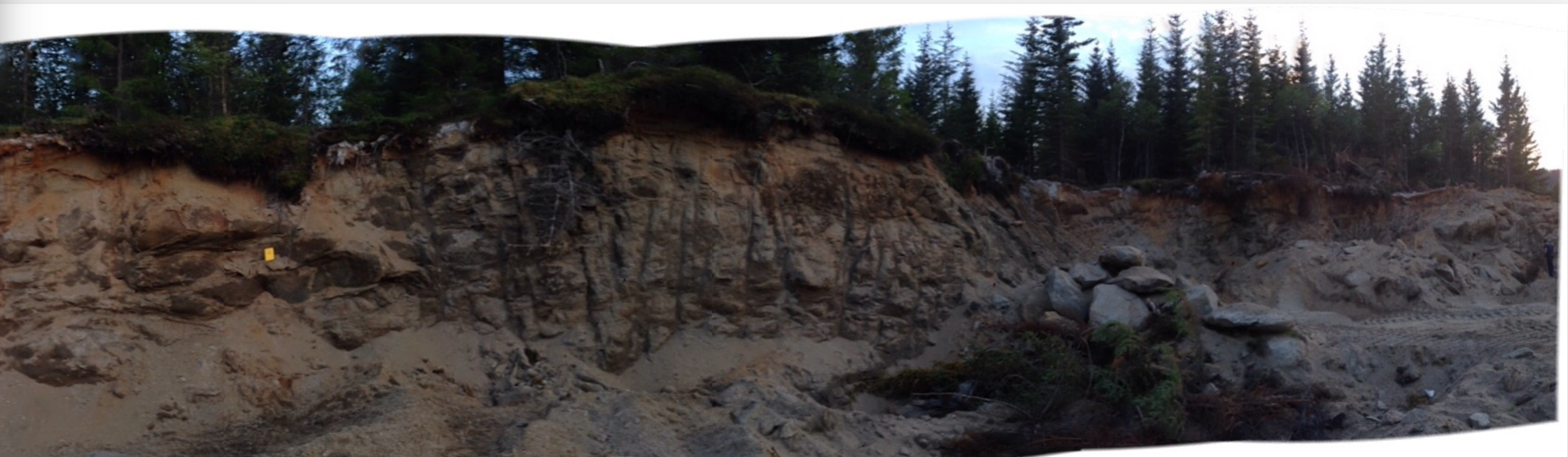

\section{Conclusion}

The Norwegian Arctic landscape displays pockets of deeply weathered profiles, which could represent the remnants of a formerly extensive weathered blanket. These weathered profiles could have been preserved in areas where glacial ice was not erosive or was stagnant. These saprolitic pockets could be the result of grusification of coarse-grained rocks developed on specific palaeolandscape features. Their relationship to weathering processes and climatic changes is uncertain. 